\title{
EVALUATION OF THE EFFECT OF POLYVINYLPYRROLIDONE AND CERTAIN ENHANCERS ON THE PERMEATION OF CORTICOSTERONE FROM TRANSDERMAL DELIVERY SYSTEMS: (PART II)
}

Fahima M. Hashem, Abdel Halim Ghanem*, Eman S. El-leithy and Dalia S. Shaker

Department of Pharmaceutics, Faculty of Pharmacy, Helwan University

*Faculty of Pharmacy, University of Utah, USA

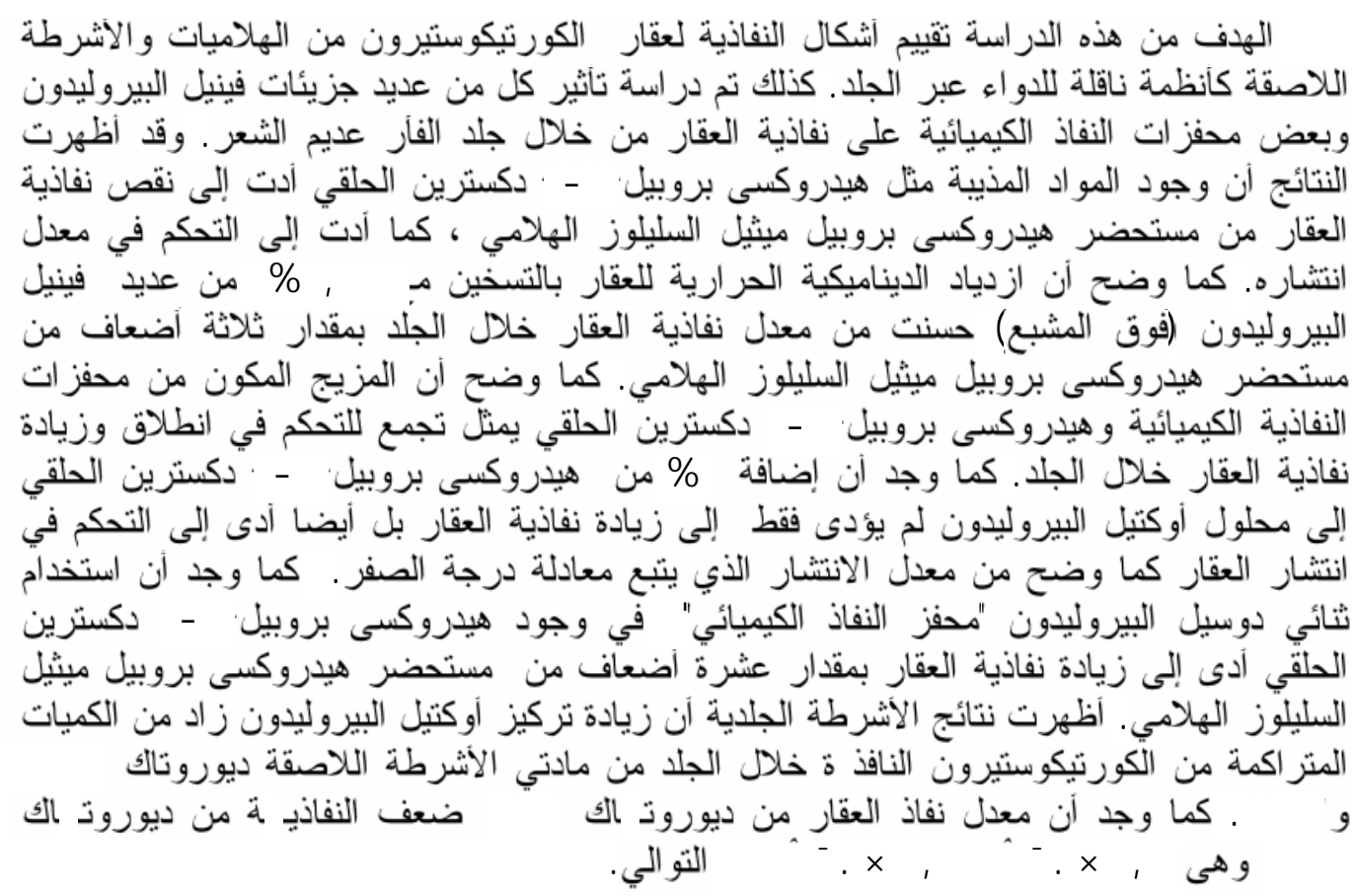

The purpose of the present study was to evaluate the permeation profiles of unlabeled corticosterone (CS) drug from gels and adhesive patches as transdermal delivery systems. The effect of polyvinylpyrrolidone and certain chemical enhancers octylpyrrolidone $(O P)$ and dodecylpyrrolidone (DDP) on the flux of drug through hairless mouse skin was also studied. The results show that presence of solubilizing agents such as hydroxypropyl-beta-cyclodextrin $(H P-\beta-C D)$ decreased the drug flux from hydroxypropyl methylcellulose (HPMC) gel dermal base and controlled the diffusion kinetics. Increasing the drug thermodynamic activity by its autoclaving with $0.25 \%$ polyvinylpyrrolidone (PVP) (supersaturation) improved the drug flux through the skin by 3 fold from HPMC gel base dermal preparations. The results also reveal that chemical enhancer/HP- $\beta$-CD mixtures represent a suitable combination for controlling the release as well as increasing the flux of drug through skin. The addition of $5 \% \mathrm{HP}-\beta-C D$ to OP solution not only increased the drug flux but also showed a controlled release that approached the zero order. Use of the chemical enhancer DDP in presence of HP- $\beta$-CD shows a 10-fold increase in CS flux from HPMC gel base. The results of transdermal patches show that increasing the concentration of $O P$ increased the cumulative amounts of Labeled corticosterone $\left({ }^{3} \mathrm{H}-\mathrm{CS}\right)$ permeated through the skin from two adhesives patches Duro-tak $\Theta 2516$ and 2287. There is a difference between the two adhesives patches in terms of skin permeation. The rate of

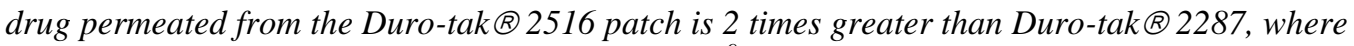
there permeability coefficient is 9.05 and $4.67 \times 10^{-9}$ respectively. 


\section{INTRODUCTION}

Transdermal delivery systems provide self-drug administration and their removal provokes an immediate reduction in the plasma level of the drug. Such system was applicable for the production of sustained and controllable levels of drug in the plasma, avoiding peaks and troughs reached with the oral or intravenous routes of administration, and thus, decreasing the risk of potential side effects. Drugs are applied to skin that act as an effective barrier to passage of substances into and out of the body for a local or systemic effect. The extent and rate of percutaneous drug absorption and transportation are influenced by skin physiology, physiochemical properties of drugs and excipients and design of delivery systems. ${ }^{1}$ Mehta, ${ }^{2}$ revealed the advantages of transdermal delivery systems and percutaneous route for systemic drug delivery. Skin is made up of several layers including stratum corneum, viable epidermis and dermis, and it contains appendages that include sweat glands, sebaceous gland and hair follicles. The outermost layer stratum corneum is the ratelimiting barrier to percutaneous drug transport. Such layer is a remarkably more effective barrier to drug transport than the epithelial barriers of gastrointestinal, nasal, buccal, vaginal or rectal routes. ${ }^{3}$ Gel formulations generally provide faster drug release compared with ointments and creams in terms of use and patient acceptability. ${ }^{2}$ Some drugs that have properties to penetrate the skin and are potent enough to be effective at low doses can be delivered transdermal gel. The combinations of polymer matrices and bioactive agents chosen must allow for the drug to diffuse through the pores or macromolecular structure of the polymer upon introduction of the delivery system into the biological environment without including any change in the polymer itself. ${ }^{4}$ Most transdermal patches are designed to release the active ingredient at a zero-order rate for a period of several hours to days following application to skin. This is especially advantageous for prophylactic treatment or maintenance therapy in chronic conditions where the patient is required to carry around oral medications and remember to take them several times a day. The following investigation was carried out to determine the effect of polyvinylpyrrolidone as well as the two chemical enhancers octyl-and dodecyl pyrrolidones on flux of corticosterone from gel and adhesive patch as models of topical preparations.

\section{EXPERIMENTAL}

\section{Materials}

Unlabeled corticosterone (CS), Sigma Chemical Company. Labeled corticosterone $\left({ }^{3} \mathrm{H}-\mathrm{CS}\right)$ at $>95 \%$ purity was purchased from American Radiolabeled Chemicals, Inc., St. Louis, MO., U. S. A., and tested for purity by methods suggested by the supplier. Hydroxypropyl-beta-cyclodextrin (HP- $\beta$-CD) was kindly supplied from Roquette Freres, France. Phosphate buffered saline (PBS) tablets, pH 7.4, were obtained from Sigma Chemical Company, St. Louis, MO., and used as received. Polyvinylpyrrolidone (PVP) K 30 (intrinsic viscosity 80-100) of molecular weight 360,000 was purchased from Sigma. Chemical Company, St. Louis, Mo. Octylpyrrolidone and dodecylpyrrolidone and sodium azide were purchased from Sigma. Chemical Company, St. Louis, Mo. Hydroxypropyl methylcellulose (HPMC) (80-120 centipoises for $2 \%$ aqueous solution, $20^{\circ}$. Duro-tak ${ }^{\circledR}$ (acrylic polymer) 387-2516 and 387-2287 were kindly supplied by National Starch and Chemical Co., Netherlands.

\section{Equipment}

Franz-type diffusion cell system, Scientific Glass Inc., California, U.S.A. Liquid scintillation counter, Model 1900 TR (TRICARB TM liquid scintillation analyzers), Packard Instrument Company, U.S.A. Liquid scintillation cocktail, Ultima Gold, high flashpoint universal LSC - Cocktail, Parked, Meriden, CT., U.S.A. Scintillation vials, Kimble Glass Inc., Vineland, New Jersey, U.S.A. Autoclave, HIRAYAMA, Amerex Instruments INC. Lafyette, California, U.S.A. Thermostatic water bath, model YB-521, American Scientific Products, McGaw Park, Illinois, U.S.A. Screw capped Pyrex culture tubes, diameter, $13 \mathrm{~mm}$; length $100 \mathrm{~mm}$; VWR Scientific, Philadelphia, PA. Para-film, laboratory film, American National Can, Chicago, Illinois, U.S.A. Millipore ${ }^{\circledR} 0.22 \mu \mathrm{m}$ filter, $25 \mathrm{~mm}$ diameter, Millipore Corporation, 
Bedford, MA, U.S.A. Series of micropipettes, Eppendorf 2000, variable volume, Brinkmann, VWR Scientific Products, Willard, Ohio, U.S.A

Animals: Female hairless mice (strain SKHHRI, 8-12 weeks old) were obtained from Charles River, Wilmington, MA.

\section{Methodology}

\section{A) Preparation of hydroxypropyl methyl- cellulose (HPMC) gels}

The hydrophilic gel (HPMC) was prepared by adding 30 gms of HPMC portion wise, while stirring to $100 \mathrm{ml}$ of saturated CS solution in phosphate buffered saline (PBS). $0.1 \% \mathrm{w} / \mathrm{v}$ sodium azide was added to the preparation as preservative. Gel bases were prepared with the following solution: (a) saturated CS in presence of $5 \%$ HP- $\beta-C D$ and chemical permeation enhancers (OP and DDP). (b) Supersaturated CS solution obtained by autoclaving excess amount of the drug with $0.25 \%$ PVP. Each 2 gms of the previously prepared gel base was loaded separately with 201 of ${ }^{3} \mathrm{H}-\mathrm{CS}$ in weighing boats.

\section{B) Preparation of 3H-CS transdermal patches \\ 401 of the radioactive drug previously} dissolved in ethanol was added to $5 \mathrm{ml}$ of the adhesive solution (acrylic polymer either 3872516 or $387-2287$ dissolved in mixture of ethanol, methanol and ethyl acetate, as received from the supplier) for each individual preparation in special mold lined with aluminum foil. In some formulations octylpyrrolidone was included in a concentration of $5 \% \mathrm{v} / \mathrm{v}$ of the preparation. The mixture was then stirred carefully to avoid the introduction of air bubbles, covered and left for 4 days to allow complete evaporation of the solvent. The product was $1.5-\mathrm{cm}$ diameter aluminumbacked adhesive film of 1-mm thickness that loaded with $40 \quad 1{ }^{3} \mathrm{H}-\mathrm{CS}$.

\section{Drug content}

The exact ${ }^{3} \mathrm{H}-\mathrm{CS}$ content of the gel and individual patches was determined after appropriate dissolution of $2 \mathrm{gms}$ gel base and the individual patches in 50- methanol. 101 of methanol solution was diluted with $10 \mathrm{ml}$ cocktail and the ${ }^{3} \mathrm{H}-\mathrm{CS}$ content of both formulations was measured by liquid scintillation counter.

In-vitro Permeation of 3H-CS from transdermal systems

\section{a) From gel formulation}

The in-vitro permeation profile of ${ }^{3} \mathrm{H}-\mathrm{CS}$ from gel was performed in Franz-type diffusion cell. The hairless mouse skin was sandwiched between the two chambers of the Franz diffusion cells. 2 gms of each gel base containing: (a) saturated CS solution in PBS, (b) $5 \%$ HP- $\beta-\mathrm{CD}$, (c) $0.25 \%$ PVP and (d) chemical permeation enhancers (OP and DDP) was loaded with $20 \quad 1{ }^{3} \mathrm{H}-\mathrm{CS}$ was evenly spread on the skin membrane in the donor chamber. The receiver compartment had a volume of $20 \mathrm{ml}$ of PBS. The cell was kept at $37^{\circ}$ with stirring of the receiver phase at 300 rpm. Sampling arms and donor apertures were occluded with Para-film. For each formula, the permeation profile of ${ }^{3} \mathrm{H}-\mathrm{CS}$ was followed for 6 hours. At time intervals ( $1 \mathrm{hr}$ each), $1000 \mathrm{~L}$ aliquots from the receiver chamber were taken, mixed with scintillation cocktail and analyzed with a liquid scintillation counter. The sample taken was replaced by the same volume of fresh PBS that added to receiver chamber to maintain a constant solution.

\section{b) From patches}

The adhesive/drug films were firmly pressed onto the center of abdominal hairless mouse skin specimen. Once adhesion to the skin surface had been confirmed the skin was quickly mounted on the flange of Franz-type diffusion cell receptor compartment such that the patch was situated precisely over the flange aperture. The donor compartment was then placed in position and the two halves of the cell sealed together with Para-film. For each transdermal patch, the permeation profile of ${ }^{3} \mathrm{H}-\mathrm{CS}$ was determined for 12 hours following the same procedure described under gel.

\section{RESULTS AND DISCUSSION}

\section{In-vitro flux of corticosterone from transdermal delivery systems}

\section{A) From gel formulation}

The results of in-vitro permeation profiles of ${ }^{3} \mathrm{H}-\mathrm{CS}$ from gel formulations through hairless mouse skin are presented in Figures (1- 
3) and the drug release behavior was analyzed in terms of the main physico-chemical parameters of the systems examined. Figure 1, presented the release profiles of ${ }^{3} \mathrm{H}-\mathrm{CS}$ from the gel base saturated with CS in absence and in presence of $5 \%$ HP- $\beta$-CD through hairless mouse skin. The results show that presence of $5 \%$ HP- $\beta-C D$ significantly decreased cumulative amounts of ${ }^{3} \mathrm{H}-\mathrm{CS}$ (dpm, disintegration per time) released in the receiver chamber by about 10 fold. This effect was attributed to decrease of free ${ }^{3} \mathrm{H}-\mathrm{CS}$ in the donor compartment as a result of complexation with cyclodextrin. ${ }^{5}$ Also, it was obvious that the presence of $5 \%$ HP- $\beta$-CD gave a constant diffusive gradient suggesting that complexation controls the diffusion pattern of the drug.

The effect of Polyvinylpyrrolidone (PVP) is presented in Figure 2, showing the release of supersaturated autoclaved CS solution in presence of $0.25 \%$ PVP. The cumulative amounts of ${ }^{3} \mathrm{H}-\mathrm{CS}$ (dpm, disintegration per time) fluxed from supersaturated CS/PVP solution is transformed to $\mathrm{mg} / \mathrm{ml}$ units in order to show the effect of supersaturation. The experimental data reveal that the drug release in autoclaved CS/PVP solution through the skin is increased by 3 fold compared to control saturated CS solution. This finding is related to increase of drug thermodynamic activity, as a result of the crystal growth inhibitory effect of PVP in supersaturated solution of the drug. Previous results of Yoneto and others, ${ }^{6}$ show that $2.3 \times 10^{-3} \mathrm{M}$ of octyl-pyrrolidone (OP) increased the flux of drugs by 10 times in transport studies. The effect of such chemical enhancers in absence or in presence 5\% HP- $\beta$ $\mathrm{CD}$ on release of CS from HPMC gel base are presented in Figures 3. The release profiles of ${ }^{3} \mathrm{H}-\mathrm{CS}$ in $2.3 \times 10^{-3} \mathrm{M}$ of $\mathrm{OP}$ and in $2.3 \times 10^{-2}$ $\mathrm{M}$ OP/ $5 \%$ HP- $\beta-\mathrm{CD}$ are presented in Figure (3), showing that both concentrations increased the drug release from HPMC gel base. The results also revealed that addition of 5\% HP- $\beta$ $\mathrm{CD}$ to $2.3 \times 10^{-2} \mathrm{M}$ of $\mathrm{OP}$ solution not only increased the drug flux 10 times but also resulted in a controlled release behavior due to drug complexation with cyclodextrin. ${ }^{5}$ This behavior is reflected by kinetics that approached to a zero order that ensures a controlled availability in-vivo. Such results are in agreement with the study of Orienti and others, $^{7}$ who reported that, the presence of complexing agents such as $\beta$-cyclodextrin in dermal bases controls the diffusion kinetics due to regulation of the amount of drug diffused through complexation. Bibby and others ${ }^{8}$ have found that the cyclodextrins modify the drug release from polymeric drug delivery systems. The permeation profile of ${ }^{3} \mathrm{H}-\mathrm{CS}$ from HPMC base was also determined in presence of $3.75 \mathrm{x}$ $10^{-4} \mathrm{M}$ dodecyl-pyrrolidone (DDP)/ 5\% HP- $\beta$ CD (Figure 3). The data revealed DDP chemical enhancer gave a 10 -fold enhancement of CS flux in addition to controlled release kinetics. The following sequence is observed for the cumulative amounts of $3 \mathrm{H}-\mathrm{CS}$ diffused as a summary of the results: $\mathrm{CS} / \mathrm{OP}=\mathrm{CS} / \mathrm{OP} /$ HP- $\beta-\mathrm{CD}=\mathrm{CS} / \mathrm{DDP} / \mathrm{HP}-\beta-\mathrm{CD}>\mathrm{CS} / \mathrm{PVP}>$ $\mathrm{CS}>\mathrm{CS} / \mathrm{HP}-\beta-\mathrm{CD}$. From these results it emerges that a suitable combination for controlled release could be obtained either from drug in OP-HP- $\beta$-CD or DDP-HP- $\beta-C D$ solutions from gel bases.

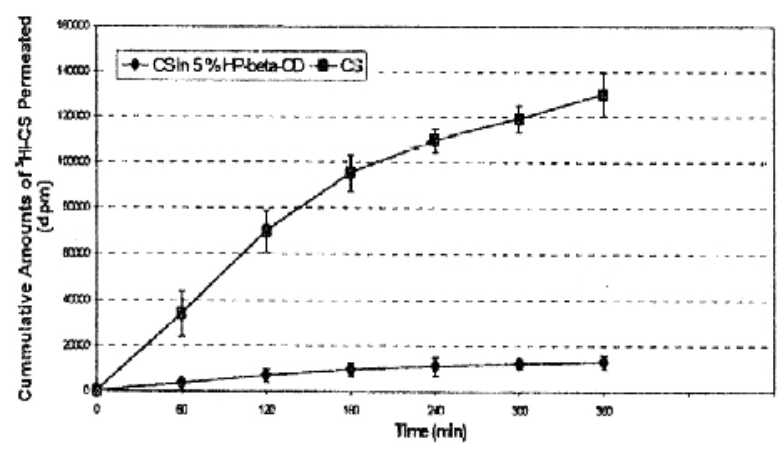

Fig. 1: Permeation profiles of ${ }^{3} \mathrm{H}-\mathrm{CS}$ through skin from HPMC gel bases prepared with saturated $\mathrm{CS}$ or saturated CS/HP- $\beta-\mathrm{CD}$ solutions.

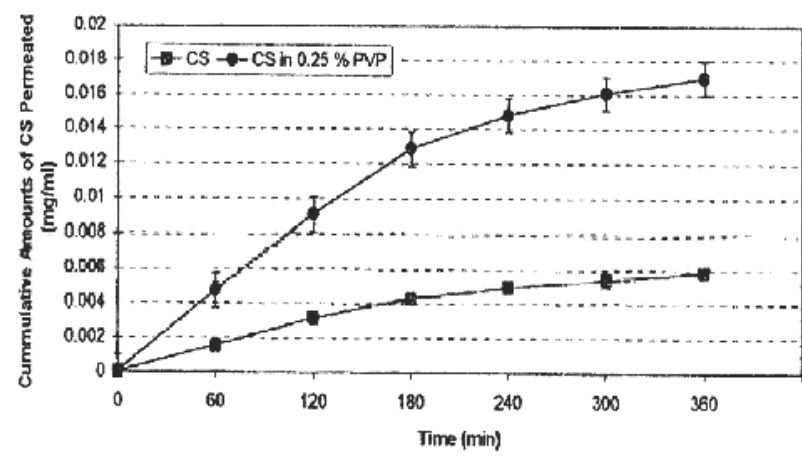

Fig. 2: Permeation profiles of ${ }^{3} \mathrm{H}-\mathrm{CS}$ through skin from HPMC gel bases prepared with saturated CS or supersaturated CS/PVP solutions. 

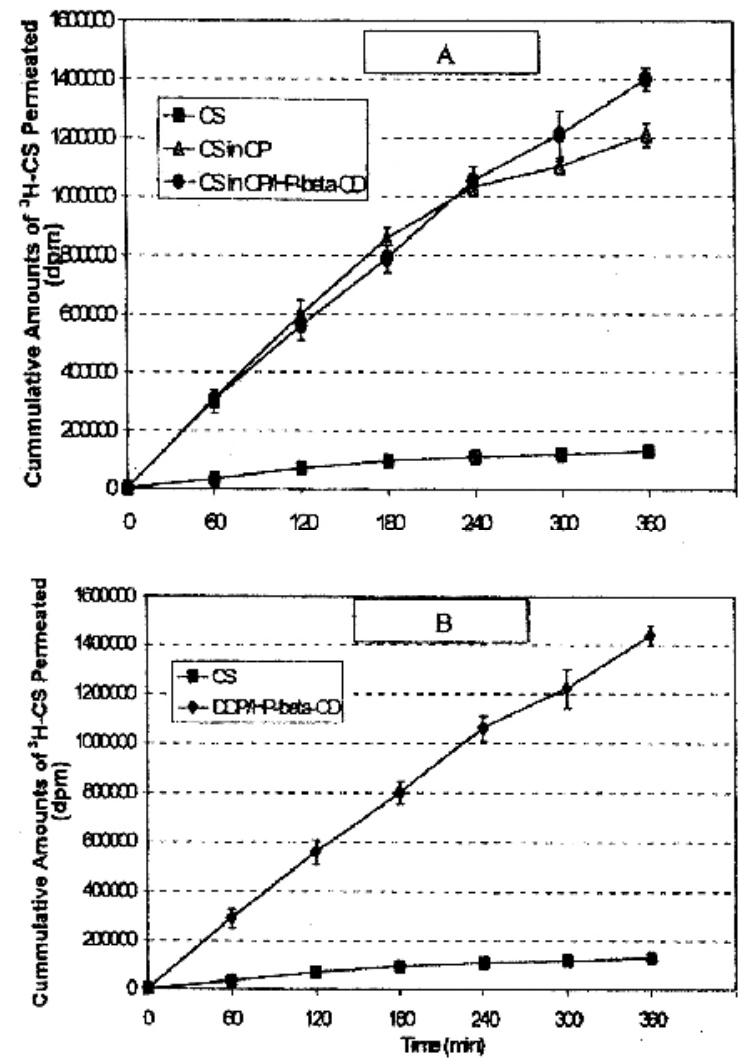

Fig. 3: Permeation profiles of ${ }^{3} \mathrm{H}-\mathrm{CS}$ through skin from HPMC gel bases prepared with saturated $\mathrm{CS}$ or saturated $\mathrm{CS}$ and: (A) $\mathrm{CS} / \mathrm{OP}$ and CS/OP/HP- $\beta-\mathrm{CD}$ solutions, (B) CS/DDP/HP- $\beta-C D$ solutions.

\section{B) From patches}

The chemical nature of a transdermal adhesive can affect the solubility of the drug. ${ }^{9}$ Adhesives containing $\mathrm{OH}$ groups were found to produce homogenous and stable patches, possibly due to hydrogen bond formation that provided good rates of drug release. ${ }^{3} \mathrm{H}-\mathrm{CS}$ was formulated as a monolithic adhesive matrix type patch. In the present study corticosterone patches were prepared using two types of polyacrylate polymers containing alcohol function groups; Duro-tak ${ }^{\circledR} 387-2516$ and 3872287, and the chemical permeation enhancer octyl-pyrrolidone was incorporated in the patches $(1.5 \mathrm{~cm}$ diameter and $1-\mathrm{mm}$ thickness).

The permeation profiles of ${ }^{3} \mathrm{H}-\mathrm{CS}$ across hairless mouse skin in absence or in presence of OP from Duro-tak 2516® and Duro-tak ${ }^{\circledR}$ 2287 are presented in Figure 4 (A and B). The profiles from both patches show an increase in the cumulative amounts of ${ }^{3} \mathrm{H}-\mathrm{CS}$ permeated through skin upon addition of the chemical permeation enhancer (OP) from both adhesive patches. The flux and permeability coefficient data for ${ }^{3} \mathrm{H}-\mathrm{CS}$ through skin from transdermal adhesive patches are presented in Table (1). The data show that there is a difference between the two adhesives Duro-tak® 2516 and $2287 \AA$ in terms of skin permeation. The rate of drug release from the former patch is 2 times greater than that from the later (the drug flux was 9.05 and $4.67 \times 10^{-9}$ from D-2516 and 2287 respectively). This result may be attributed to the cross-linked structure of Durotak® 2516 that may provide a more tortuous pathway for drug release than adhesive $2287 \AA$, which lacked cross-linking. Jeans and Heard ${ }^{10}$ previously reported this difference in adhesives chemical structure. The results are also in agreement with that of Park and others. ${ }^{11}$ They reported that incorporation of chemical permeation enhancers such as DMSO, oleic acid and lauryl alcohol in the transdermal patch was essential to increase the permeation rate of Captopril from transdermal patches.
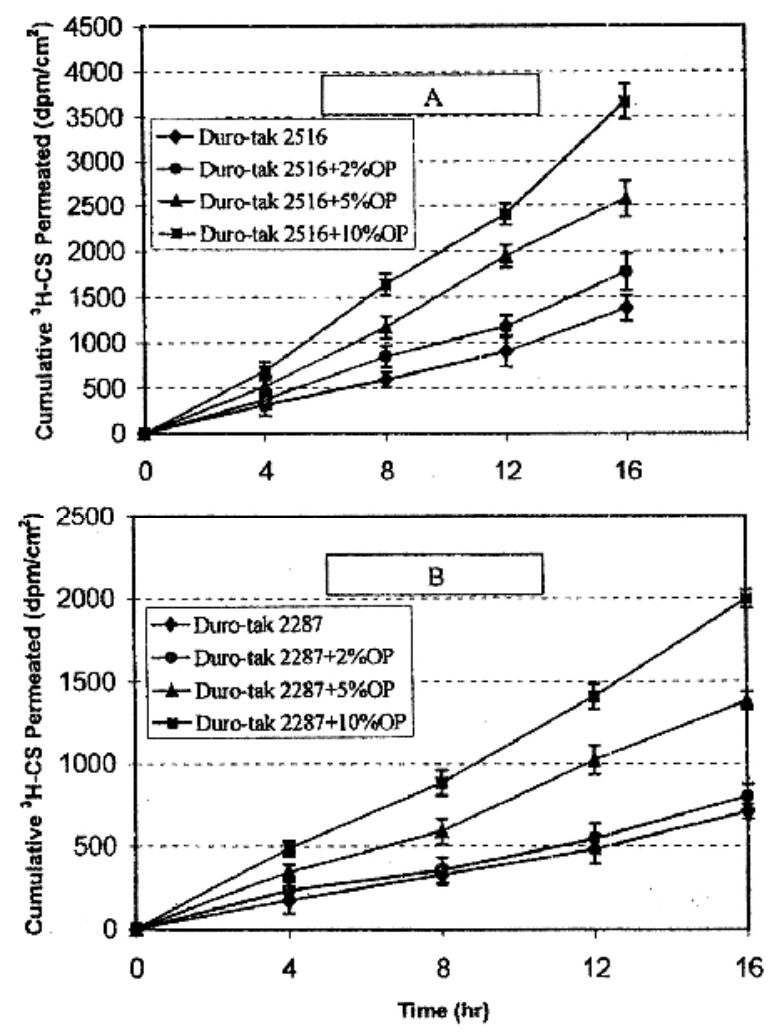

Fig. 4: Permeation profiles of ${ }^{3} \mathrm{H}-\mathrm{CS}$ across hairless mouse skin from:

(A) Transdermal Duro-tak® 2516 patches.

(B) Transdermal Duro-tak® 2287 patches. 
Table 1: In-vitro flux and permeability coefficient of ${ }^{3} \mathrm{H}-\mathrm{CS}$ across hairless mouse skin from transdermal adhesive patches.

\begin{tabular}{|c|c|c|}
\hline Patches Constituents & $\begin{array}{c}\text { Flux } \\
\left(\mathrm{dpm} / \mathrm{cm}^{2} . \mathrm{hr}\right) \\
\pm \mathrm{SD} \\
\end{array}$ & $\begin{array}{c}\text { Permeability } \\
\text { Coefficient } \\
(\mathrm{cm} / \mathrm{sec}) \\
\end{array}$ \\
\hline${ }^{3} \mathrm{H}-\mathrm{CS}(40 \mu \mathrm{l})$ in Duro-tak $\circledast 387-2516$ & $333.29 \pm 45$ & $9.05 \times 10^{-9}$ \\
\hline $\begin{array}{l}{ }^{3} \mathrm{H}-\mathrm{CS}(40 \mu \mathrm{l}) \text { in Duro-tak } ® 387-2516+ \\
\text { octyl-pyrrolidone } 2 \%\end{array}$ & $433.71 \pm 73$ & $11.7 \times 10^{-9}$ \\
\hline $\begin{array}{l}{ }^{3} \mathrm{H}-\mathrm{CS}(40 \mu \mathrm{l}) \text { in Duro-tak } \circledast 387-2516+ \\
\text { octyl-pyrrolidone } 5 \%\end{array}$ & $657.71 \pm 63$ & $17.87 \times 10^{-9}$ \\
\hline $\begin{array}{l}{ }^{3} \mathrm{H}-\mathrm{CS}(40 \mu \mathrm{l}) \text { in Duro-tak } \circledast 387-2516+ \\
\text { octyl-pyrrolidone } 10 \%\end{array}$ & $902.86 \pm 75$ & $24.5 \times 10^{-9}$ \\
\hline${ }^{3} \mathrm{H}-\mathrm{CS}(40 \mu \mathrm{l})$ in Duro-tak ${ }^{\circledR} 387-2287$ & $171.86 \pm 58$ & $4.67 \times 10^{-9}$ \\
\hline $\begin{array}{l}{ }^{3} \mathrm{H}-\mathrm{CS}(40 \mu \mathrm{l}) \text { in Duro-tak }{ }^{\circledR} 387-2287+ \\
\text { octyl-pyrrolidone } 2 \%\end{array}$ & $190.86 \pm 45$ & $5.18 \times 10^{-9}$ \\
\hline $\begin{array}{l}{ }^{3} \mathrm{H}-\mathrm{CS}(40 \mu \mathrm{l}) \text { in Duro-tak } \circledast 387-2287+ \\
\text { octyl-pyrrolidone } 5 \%\end{array}$ & $343.43 \pm 101$ & $9.3 \times 10^{-9}$ \\
\hline $\begin{array}{l}{ }^{3} \mathrm{H}-\mathrm{CS}(40 \mu \mathrm{l}) \text { in Duro-tak }{ }^{\circledR} 387-2287+ \\
\text { octyl-pyrrolidone } 10 \%\end{array}$ & $490.40 \pm 45$ & $13.3 \times 10^{-9}$ \\
\hline
\end{tabular}

The following sequence is observed for the cumulative ${ }^{3} \mathrm{H}-\mathrm{CS}$ amounts released as a summary of the results: Duro-tak ${ }^{\circledR} 2516+10$ $\%$ OP > Duro-tak 2516 ® $+5 \%$ OP > Duro$\operatorname{tak}{ }^{\circledR} 2287+10 \%$ OP $>$ Duro-tak $® 2516+2$ $\%$ OP > Duro-tak ® $2287+5 \%$ OP > Durotak ${ }^{\circledR} 2516>$ Duro-tak $\AA 2287+2 \%$ OP> Duro-tak ${ }^{\circledR} 2287$. A similar results in the order of increasing CS release rate from Duro-tak patches was found by Chedgzoy et al. ${ }^{12}$ that reported that the trend for increased triclosan release from transdermal adhesive formulations was Duro-tak 2051 > $2516>2287$.

\section{Conclusion}

From the above results it is concluded that using of solubilizing agents such as HP $\beta-C D$ decreased the drug flux from HPMC gel base and controlled the diffusion kinetics due to regulation of the amount of drug diffused through complexation. Increasing the drug thermodynamic activity by autoclaving the drug with $0.25 \%$ PVP (supersaturation) improved the drug flux through the skin by 3 fold from HPMC gel base. The results also revealed that chemical enhancer/HP- $\beta-C D$ mixture represented a suitable combination for controlling the release as well as increasing the flux of drug through skin. The addition of 5\% HP- $\beta$-CD to OP solution not only increase the drug flux but also showed a controlled release behavior due to complexation with cyclodextrin that approaching to a zero order. Use of DDP chemical enhancer also show a 10fold increase in CS flux from HPMC gel base. The incorporation of the two permeation enhancers in the transdermal patches was essential to increase the permeation rate of corticosterone from the patches. Increasing the concentration of OP increased the cumulative amounts of ${ }^{3} \mathrm{H}-\mathrm{CS}$ permeated through the skin. There is a difference between the two adhesives Duro-tak ${ }^{\circledR} 2516$ and 2287 in terms of skin permeation. The rate of drug release from the former patch is 2 times greater than that from the later.

\section{Acknowledgment}

This work was carried out in the Department of Pharmaceutics and pharmaceutical chemistry, University of Utah, USA, as a grant for D. Shaker. The authors 
thanks for Prof. Dr. W. I. Higuchi for providing the necessary Facilities.

\section{REFERENCES}

1- H. C. Ansel, L. V. Jr. Allen and N. G. Popovich (Eds), Pharmaceutical Dosage Forms and Drug Delivery Systems. $7^{\text {th }}$ Ed. New York, NY, Chap. 2 (1999).

2- R. Mehta, Topical and transdermal drug delivery: what a pharmacist needs to know. Report from InetCE "world wide web" (2002).

3- C. Surber, Pharm. Res., 7, 1320-24 (1990).

4- V. V. Ranada, and M. A. Hollinger, Drug Delivery Systems. CRC Press, Boca Raton, Fl., Chap. 1 (1996).

5- F. M. Hashem, A. H. Ghanem, E. S. Elleithy and D. S. Shaker, In press in Bull. Fac. Pharm. Cairo Univ, Egypt, 41 (2) (2003).
6- K. Yoneto, S. K. Li, W. I. Higuchi and S. Shimabayashi, J. Pharm. Sci., 87, 209-214 (1998).

7- I. Orienti, V. Zecchi, G. Ceschel and A. Fini, Eur. J. Drug Metab. Pharmacokinet., Sept. 3, 466-472 (1991).

8- D. C. Bibby, N. M. Davies, and I. G. Tucker, Int. J. Pharm., 197, 1-11 (2000).

9- P. Mayorga, F. Puisieux, and G. Couarraze, Int. J. Pharm., 132, 71-79 (1996).

10- C. W. Jeans, and C. M. Heard, Int. J. Pharm., 189, 1-6 (1999).

11- E. S. Park, S-J. Chang, Y-S. Rhee, and SC. Chi, Drug Dev. Ind, Pharm., 27, 975980 (2001).

12- P. Chedgzoy, G. Winckle, and C. M. Heard, Int. J. Pharm., 235, 229-236 (2002). 